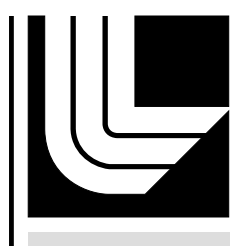

LAWRENCE LIVERM ORE N A TIO N A L LABORATORY

Evaluation of Rupture Panels

$\mathrm{M} 1, \mathrm{M} 2$, and $\mathrm{M} 3$

T. Shen

January 24, 2013 
This document was prepared as an account of work sponsored by an agency of the United States government. Neither the United States government nor Lawrence Livermore National Security, LLC, nor any of their employees makes any warranty, expressed or implied, or assumes any legal liability or responsibility for the accuracy, completeness, or usefulness of any information, apparatus, product, or process disclosed, or represents that its use would not infringe privately owned rights. Reference herein to any specific commercial product, process, or service by trade name, trademark, manufacturer, or otherwise does not necessarily constitute or imply its endorsement, recommendation, or favoring by the United States government or Lawrence Livermore National Security, LLC. The views and opinions of authors expressed herein do not necessarily state or reflect those of the United States government or Lawrence Livermore National Security, LLC, and shall not be used for advertising or product endorsement purposes.

This work performed under the auspices of the U.S. Department of Energy by Lawrence Livermore National Laboratory under Contract DE-AC52-07NA27344. 


\section{Evaluation of Rupture Panels M1, M2 and M3}

Tien $\mathrm{H}$. Shen

$1 / 10 / 2013$

In December 2012, four rupture panels, from Q42T, Q22T, Q22B and Q45B, have been found leaking during inspection. Three of these panels, which have only been in service since April 2012, belong to the most recently purchased lots in 2011. These three panels are:

\begin{tabular}{|c|c|}
\hline Lab ID & Panel ID \\
\hline M1 & AAA02-101378-OA-0427 \\
\hline M2 & AAA02-101378-OA-0434 \\
\hline M3 & AAA02-101378-OA-0326 \\
\hline
\end{tabular}

The locations where the leaks occurred along the scored lines in each panel are illustrated in Figure 1.
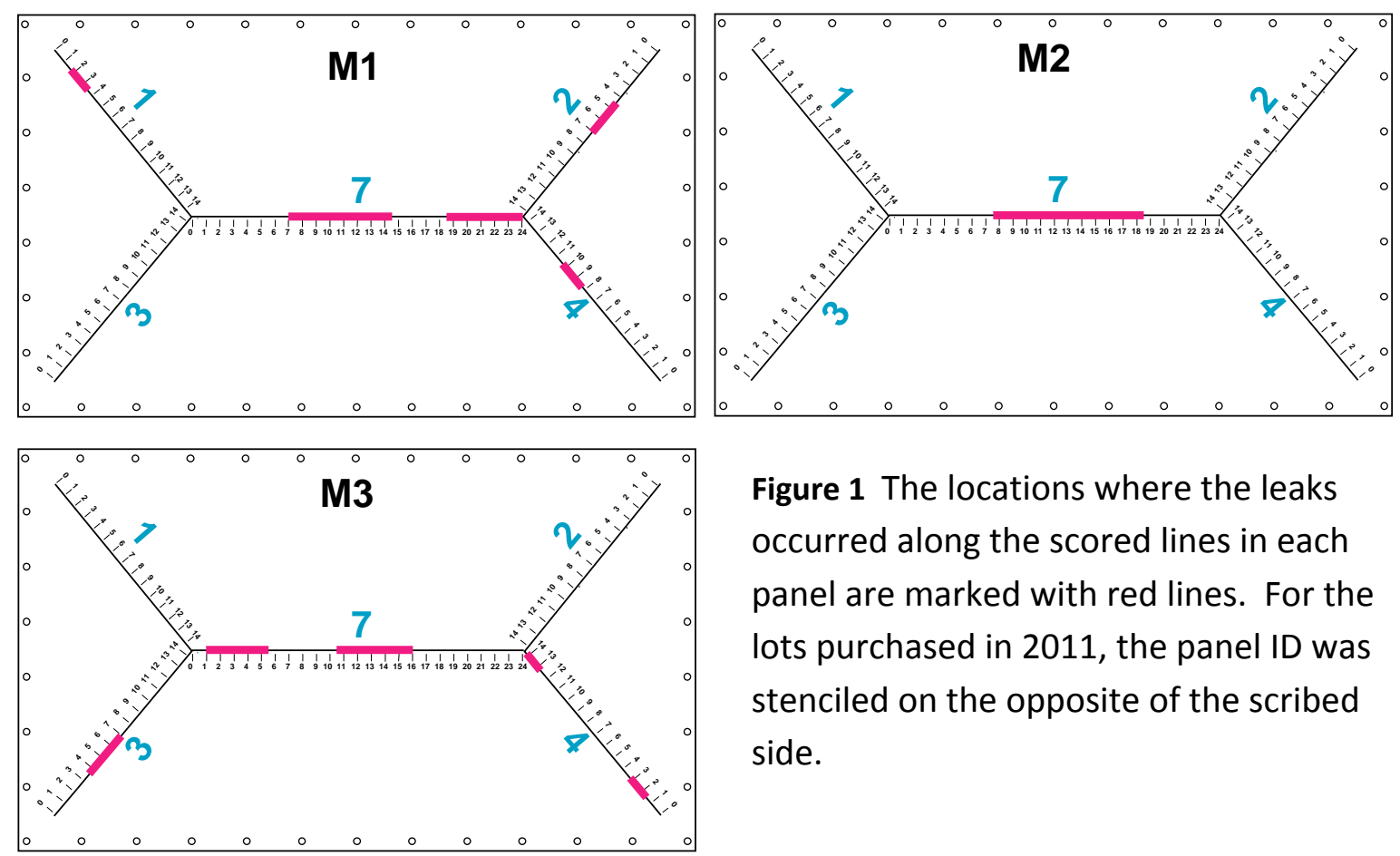

Figure 1 The locations where the leaks occurred along the scored lines in each panel are marked with red lines. For the lots purchased in 2011, the panel ID was stenciled on the opposite of the scribed side.

We had studied two brand new panels (N1 \& N2) from the 2011 lots in April 2012 $2^{1,2}$. The conclusion was that the cracks will develop in the panels since the unscored depth in many locations along the scored lines was less than $100 \mu \mathrm{m}$ as illustrated in Figures $\mathbf{6}$ and $\mathbf{7}$ in Ref. 1 and Figure $\mathbf{2}$ in Ref. 2. Coincidentally, the predicted failure sites, as shown in the Figure $\mathbf{7}$ in Ref. 1, are strikingly similar to the actual leak locations found in panels $\mathbf{M} \mathbf{1}$ and $\mathbf{M} \mathbf{3}$ as shown in Figure 1. 


\section{Fatigue Crack Initiation}

Figure 2 below shows the progression of fatigue crack development as affected by the flopping of the panel. As shown in Figure 2a, the bottom surface of the panel was plastically deformed inward due to the flopping of the panel during service. The fatigue crack developed and grew as shown in Figure $\mathbf{2 b}$, and the curvature of the kink at the bottom surface shortened. In the final stage as shown in Figure $\mathbf{2 c}$, the kink sharpened to a point that causing the crack to penetrate through the whole unscored thickness. Thus, to minimize the flopping of panel during service will help to reduce the tendency of fatigue crack initiation and growth.
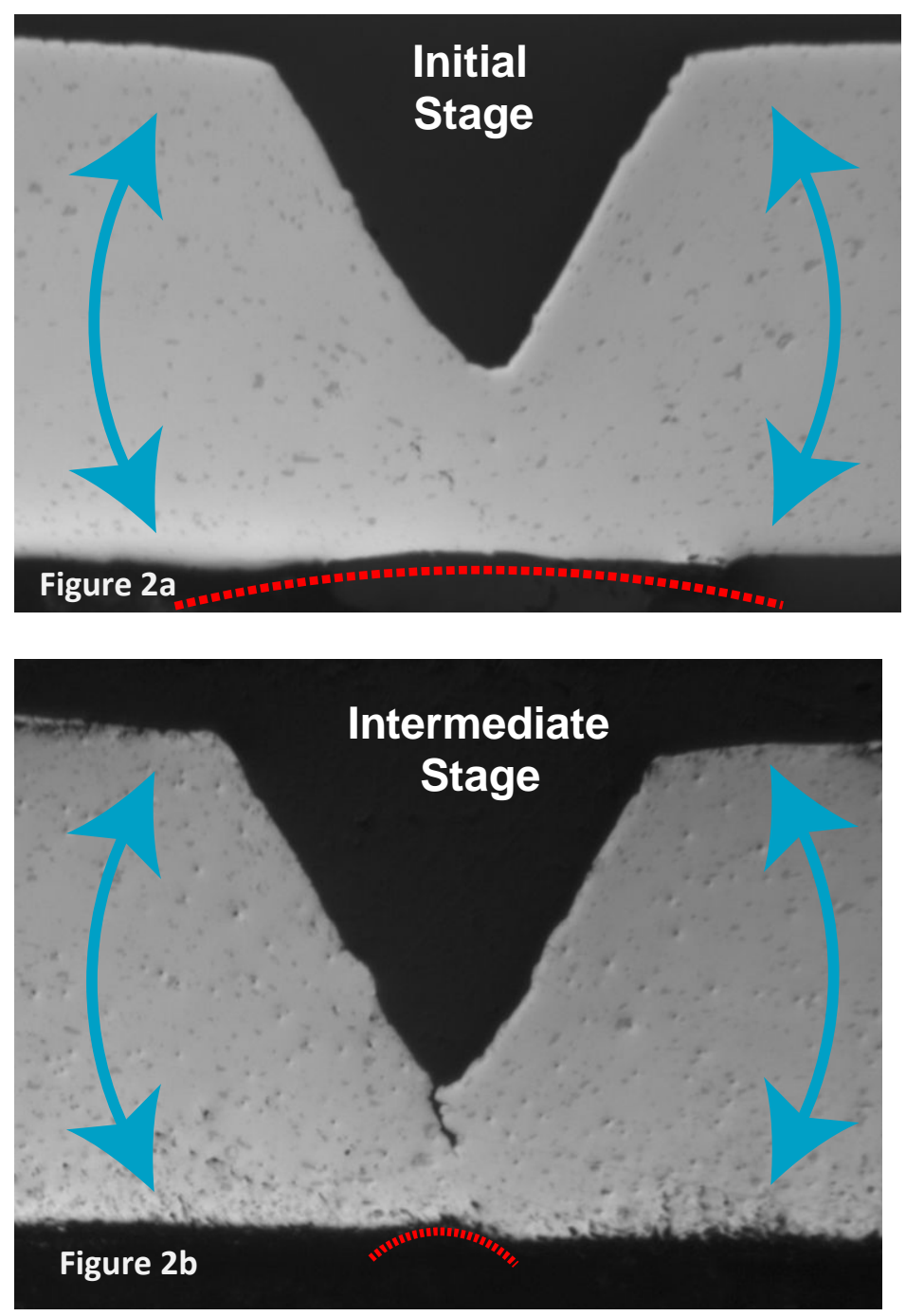

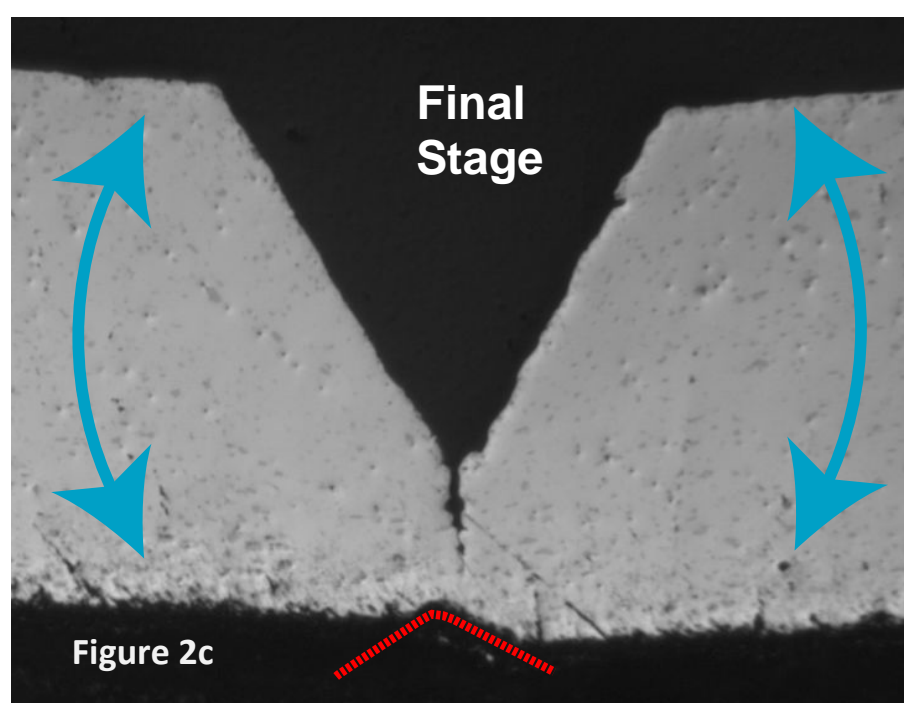

Figure 2 shows the progression of the fatigue crack growth, and the evidence of the flopping of the rupture panel during service. 


\section{Scored Depth Measurements}

Figures $\mathbf{3}$ and $\mathbf{4}$ summarize the scored depth measurements for panel $\mathbf{M} \mathbf{1}$ and $\mathbf{M} \mathbf{2}$, respectively. Since the results are consistent with all data we have reported previously ${ }^{1,2,3,4}$, the $\mathbf{M} 3$ panel was not measured.
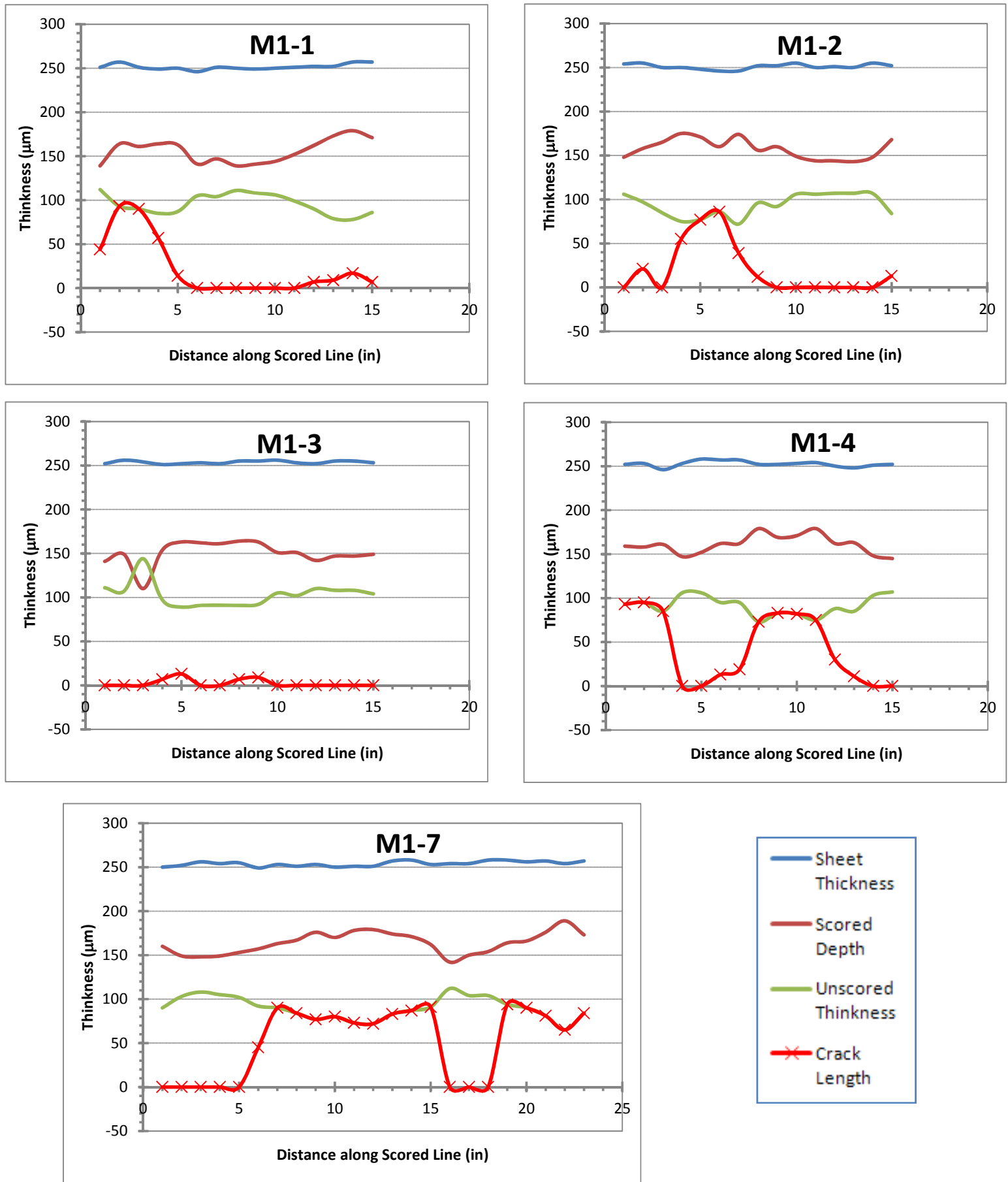

Figure 3 The results of the scored profile measurements for panel M1. 

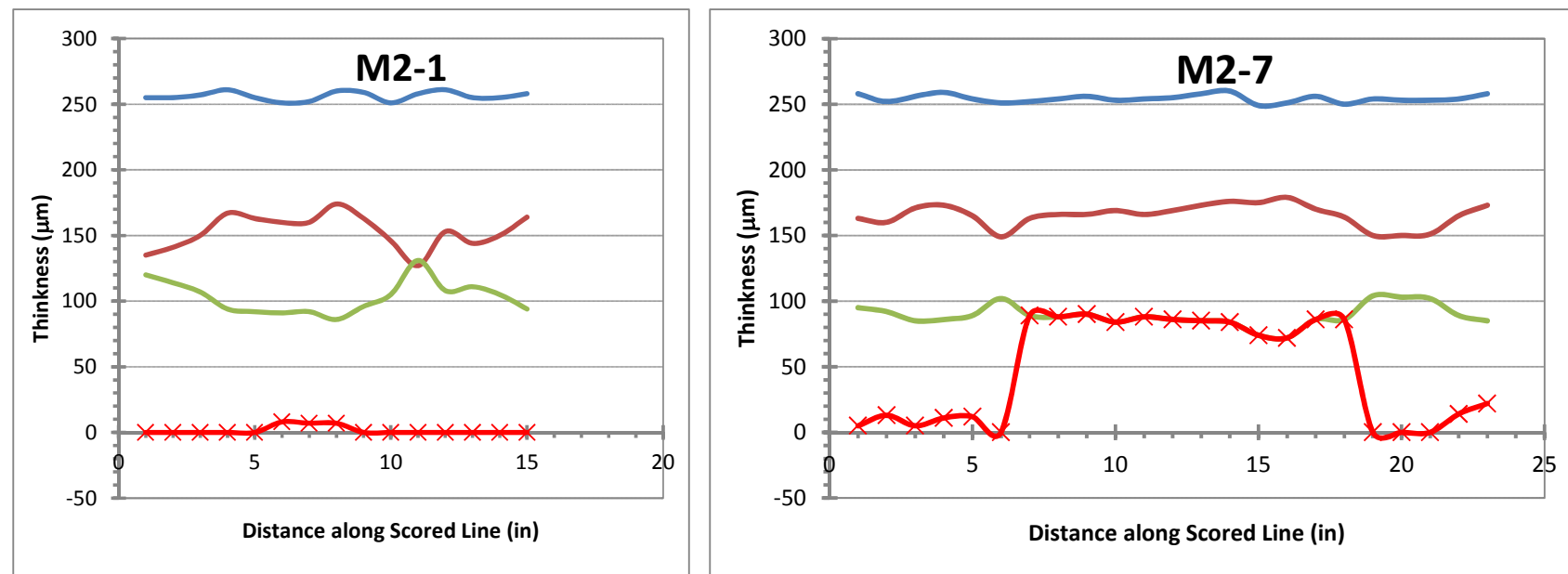

Figure 4 The results of the scored profile measurements for panel M2.

The scored profiles in these two panels have the same sharp V-shape, flat bottom, and round bottom as reported in Figure 4 in Ref. 1. The fatigue cracks occurred in most locations where the scored depths are less than $100 \mu \mathrm{m}$ and the scored profiles have a sharp V-shape. However, if the unscored depth is less than $100 \mu \mathrm{m}$, the flat bottom shape can still develop fatigue crack as observed in several locations.

The panel M2 only has the Scored Line 7 leaked. As shown in Figure 4, the Scored Line 1 shows that most scored depths are around and above $100 \mu \mathrm{m}$. Although some fatigue cracks did initiate, but they had not yet grown substantially. Similar condition could be seen at the panel M1 at the Scored Line $\mathbf{3}$ as shown in Figure 3.

These results are consistent with our previous finding that the fatigue crack tends to initiate and grow at the locations where the unscored depth falls below $100 \mu \mathrm{m}$, and eventually causes the rupture panel to leak.

\section{Conclusions}

- The failure of the three newly acquired 2011 rupture panels reaffirm our previous finding that the fatigue crack tends to initiate and grow at the locations where the unscored depth falls below $100 \mu \mathrm{m}$.

- Three methods can be used to increase the service life of the rupture panel. These are:

1. using different aluminum alloy, such as AA5052-O or AA5052-H32, with better fatigue strength,

2. scoring with a flat or a rounded bottom profiles,

3. reducing the flopping of rupture panel during service. 


\section{References}

1. Report by Tien Shen dated 4/13/2012, entitled "Evaluation of Rupture Panels Q25T, Q23T \& New Panel S/N 0424".

2. Report by Tien Shen dated 4/25/, entitled "Evaluation of New Rupture Panels".

3. Report by Tien Shen dated 2/29/2012, entitled "Failure Analysis of Rupture Panels Q32B \& Q35B".

4. Report by Tien Shen dated 3/14/2012, entitled "Additional Measurements of Rupture Panels". 